\title{
Evaluación de Pseudomona spp. y Coliformes asociados a parámetros abióticos en fuentes de agua subterráneas de la región de Azuero
}

\author{
Alexis De La Cruz ${ }^{1 *}$ \\ ${ }^{1}$ Docente e investigador de la Universidad de Panamá, Investigador del Ministerio de Salud, \\ Departamento de Calidad de Agua \\ * Autor para correspondencia. E-mail: alexisdelac@gmail.com
}

Recibido: 8 de julio de 2019

Aceptado: 12 de agosto de 2019

\begin{abstract}
Resumen
En las aguas subterráneas se transportan muchos parásitos, bacterias coliformes y otras especies como la Pseudomona aeruginosa, Klebsiela, Enterococos, entre otros. Siendo una peligrosa fuente de toxiinfecciones y Enfermedades gastrointestinales. El objetivo de este trabajo fue determinar la ocurrencia de Pseudomona aeruginosa y coliformes, en estación seca y lluviosa, en pozos de aguas subterráneas de la Provincia de Herrera y Los Santos y su relación con parámetros fisicoquímicos. Este estudio fue no experimental, que consistió en tomar al azar 15 pozos de agua subterránea en la Provincia de Los Santos y La Provincia de Herrera tanto en temporada seca y lluviosa, se procedió a determinar la ocurrencia de Pseudomonas spp., y coliformes mediante filtración por membrana, con la medición de parámetros físico químicos de campo. Los resultados, arrojaron que los niveles de crecimiento de P. aeruginosa en los pozos subterráneos de la Provincia de Los Santos, indican que es mayor en cantidades significativas en ambas épocas en comparación con la provincia de Herrera, la época lluviosa presentó una mayor ocurrencia de P. aeruginosa en comparación con la época seca, Los parámetros fisicoquímicos se mantuvieron constantes en las dos épocas de estudio, Concluimos que los niveles de cloro residual en ambas Provincias, en lo que concierne a las épocas en estudio fueron, encontrados valores casi aceptables para la Provincia de Herrera pero cierto incumplimiento para la Provincia de Los Santos.

Palabras clave: Pseudomona spp., Coliformes, Agua Subterránea.
\end{abstract}

\begin{abstract}
In the groundwater are conveyed many parasites, coliform bacteria and other species such as the Pseudomona aeruginosa, Klebsiela, Enterococci, aerobic mesophilic, among others. Being a dangerous source of poisoning and gastrointestinal diseases. The main objective of this study was to determine the occurrence or absence of $P$. aeruginosa in dry and rainy season in Wells of groundwater in the province of Herrera and Los Santos, and its relationship with physicochemical parameters. This study was non-experimental, which consisted in taking random 15 wells of groundwater in the province of Herrera and Los Santos province both in dry season and rainy, was to determine the occurrence of Pseudomonas spp. with measuring chemical physical field parameters. Results, showed that the levels
\end{abstract}


of growth of P. aeruginosa in groundwater from wells of the Los Santos province, indicate that it is higher in significant quantities in both periods compared to the province of Herrera, the rainy season presented a greater occurrence of P. aeruginosa in comparison with the dry season, physicochemical parameters were kept constant in the two periods of study, concluded that the levels of residual chlorine in both provinces the maximum values required by the standard of Quality of water drinking DGNT-COPANIT 23-395-99, in regards to the times study were, found almost acceptable values for the province of Herrera but certain failure for the province of Los Santos.

Key words: Pseudomona spp, Coliforms, underground water.

\section{Introducción}

El agua subterránea es uno de los recursos más valiosos y asequibles, aunque nuestras percepciones con respecto al ambiente sub-superficial del que procede son a menudo poco claras e incorrectas (Vargas, 2004).

En las aguas subterráneas se transportan muchos parásitos, bacterias coliformes y otras especies como la Pseudomona aeruginosa, Klebsiella, Enterococcus spp., Mesofilos aerobios, entre otros. Siendo una peligrosa fuente de toxiinfecciones y Enfermedades gastrointestinales en la población consumidora de esta agua (Campos et al.2002).Por tal motivo es importante el estudio de la calidad microbiológica y fisicoquímicas en los municipios de La Paz y San Diego, para identificar los posibles agentes y causas que generan enfermedades de origen hídrico y peligros sanitarios, determinando los agentes patógenos que alteran la calidad de las aguas subterráneas, tomando dichos estudios como base para el control y tratamientos de estas aguas.

Por su tolerancia a una amplia variedad de condiciones físicas se comporta como un patógeno oportunista eficaz. Su papel como patógeno responsable de infecciones comunitarias y nosocomiales está plenamente reconocido y resulta problemática la elección del antimicrobiano más adecuado. Esto se debe a que posee una elevada resistencia intrínseca a múltiples antibióticos y a una extraordinaria capacidad para adquirir nuevos mecanismos de resistencia, principalmente por mutaciones. (Jorgensen, 2000)

El grupo Pseudomonas está constituido por bacilos aerobios gramnegativos y móviles, algunos de los cuales producen pigmentos solubles en agua. Las especies del género Pseudomonas se identifican sobre la base de varias características fisiológicas. Una de las propiedades más notables de Pseudomonas es la gran variedad de compuestos orgánicos que utilizan como fuente de carbono y energía (ONTIVEROS, 1983). Peudomonas aeruginosa, no es un parásito obligatorio, puede ser fácilmente encontrada en el suelo y se comporta como desnitrificante, teniendo un papel importante en el ciclo del nitrógeno en la naturaleza (SOARES, 1996).

El objetivo de este trabajo de investigación, fue valuar la ocurrencia de Pseudomona spp., y coliformes y su relación a parámetros físico químicos de algunos pozos en la Región de Azuero. 


\section{Materiales y Método}

\subsubsection{Ubicación de sitios de estudio}

Esta investigación se llevó a cabo, en algunos Pozos de Agua Profunda en diferentes Comunidades y Distritos las Provincias de Herrera y Los Santos respectivamente.

Los análisis se realizaron seguidamente en las plantas potabilizadoras de Herrera (Ingeniero Roberto Reyna) y Los Santos (Rufina Alfaro).

Cuadro 1: Sitio de muestreo de la provincia de Herrera, evaluados los meses de noviembre 2016 y marzo 2017.

\begin{tabular}{|c|c|c|}
\hline NUMERO & LOCALIDAD & UBICACIÓN (NOMENCLATURA) \\
\hline 01 & CHUPAMAPA & B 8 \\
\hline 02 & LOS POZOS & B 11 \\
\hline 03 & LOS POZOS & B 12 \\
\hline 04 & LOS POZOS & B 13 \\
\hline 05 & $\mathrm{OCU}$ & B 9 \\
\hline 06 & $\mathrm{OCU}$ & B 11 \\
\hline 07 & $\mathrm{OCU}$ & B 13 \\
\hline 08 & $\mathrm{OCU}$ & B 15 \\
\hline 09 & PESE & B 3 \\
\hline 10 & PESE & B 7 \\
\hline 11 & PESE & B 9 \\
\hline 12 & PESE & B 10 \\
\hline 13 & SANTA MARIA & B 2 \\
\hline 14 & SANTA MARIA & B 3 \\
\hline 15 & SANTA MARIA & B 4 \\
\hline
\end{tabular}


Cuadro 2: Sitio de muestreo de la provincia de Los Santos, evaluados los meses de noviembre 2016 y marzo 2017.

\begin{tabular}{|l|l|l|}
\hline NUMERO & LOCALIDAD & UBICACIÓN (NOMENCLATURA) \\
\hline 01 & EL CARATE & B 7 \\
\hline 02 & EL COCAL & B 9 \\
\hline 03 & EL COCAL & B 13 \\
\hline 04 & EL SESTEADERO & B 8 \\
\hline 05 & EL SESTEADERO & B 9 \\
\hline 06 & LAS CRUCES & B 4 \\
\hline 07 & LAS CRUCES & B 7 \\
\hline 08 & LAS PALMAS & B 6 \\
\hline 09 & LAS PALMAS & B 13 \\
\hline 10 & LAS TABLAS & B 53 \\
\hline 11 & TAS TABLAS & B 54 \\
\hline 12 & SABANAGRANDE & B 6 \\
\hline 13 & SABANAGRANDE & B 7 \\
\hline 14 & & B 7 \\
\hline
\end{tabular}

\subsubsection{Diseño experimental}

Este estudio fue no experimental, que consistió en tomar al azar 15 pozos de agua subterránea en la Provincia de Los Santos y La Provincia de Herrera tanto en época seca y lluviosa. Se tomaron $100 \mathrm{ml}$ de muestras para los estudio microbiológico y $300 \mathrm{ml}$ para los parámetros fisicoquímicos de agua en cada pozo de agua subterránea, 60 muestras por provincia (Los Santos y Herrera) durante 4 semanas de muestreo, con un total de 120 muestras, tanto en época seca y lluviosa. 


\subsection{Metodología de campo}

\subsubsection{Toma de Muestras}

Se procedió a colectar la muestra según lo descrito en el (Methods for the Examination of Water and Wastewater) (APHA,1999) Se tomaron 2 muestras por pozos de agua subterránea con envases previamente esterilizado, los grifos de los pozos fueron esterilizados con alcohol al 70\% seguidamente se flameo el grifo y se dejó correr el agua por aproximadamente 3 minutos; se midieron el pH y Cloro Residual en campo seguidamente se tomaron $300 \mathrm{ml}$ de agua, para la evaluación físico química (alcalinidad y conductividad) la segunda muestra se tomaron $100 \mathrm{ml}$ para evaluación microbiológica los cuales fueron transportadas en hielera a temperatura de 4 a $5^{\circ} \mathrm{C}$. Se procedió a tomar 15 muestras de pozos de agua subterráneas al azar de la provincia de Herrera de igual manera para la provincia de Los Santos.

\subsection{Metodología de laboratorio}

\subsubsection{Técnicas Microbiológicas para el Análisis del Agua}

Después de ser tomadas fueron llevadas a las plantas potabilizadoras Roberto Reyna y Rufina Alfaro respectivamente en una caja térmica que mantenga una temperatura aproximada de $4-5 \mathrm{C}^{\circ}$. se utilizara el método de membrana filtrante de acuerdo al Standard Method (1995); que consiste en verter $100 \mathrm{ml}$ de la muestra en un embudo previamente esterilizado en el cual se colocará una membrana filtrante con una porosidad de $0.45 \mu \mathrm{m}$ con el propósito de retener los microorganismos deseados, seguidamente será retirada la membrana y será colocada en un plato Petri que contenga agar Cetrimides que es un medio para la detección de Pseudomonas spp basado en la producción de fluorescina (marcador fluorescente en diversos ensayos químicos y biológicos debido a que exhibe fluorescencia).

La misma será incubada a $37^{\circ} \mathrm{C}$ durante 24 horas, lo mismo será con el propósito de determinar la bacteria Pseudomona aeruginosa en cada muestreo por provincia tanto en época seca y lluviosa.

\subsubsection{Técnica de Filtro de Membrana}

La técnica de filtración de los líquidos es una técnica que se ha utilizado desde principios de la humanidad. La asociación entre membranas de filtración ha permitido desarrollar técnicas de filtración de líquidos, tales como las que conocemos hoy.

Esta técnica es rápida y sencilla de estimar. Consiste en filtrar un volumen de $100 \mathrm{ml}$ o volúmenes menores, según la densidad bacteriana con la ayuda del vacío, la muestra de agua líquida o solución de agua, a través de un filtro de una membrana estéril de celulosa de 0.45 micrómetros de diámetro; luego el filtro de coloca sobre una almohadilla absorbente en una caja Petri, la caja de contiene el disco y la almohadilla son colocadas en posición invertida con el medio de cultivo específico y se incuba a la temperatura adecuada. 


\subsection{Análisis Estadístico}

Para los análisis de los resultados microbiológicos de Pseudomonas, coliformes y los parámetros físicos -químicos. Se utilizó cuadros de ANOVA, mediante un diseño completamente al azar, pruebas de LSD y correlación entre las bacterias y los análisis físico-químicos para medir la relación entre ambos factores. Estos análisis se llevaron a cabo mediante el programa estadístico sistema SAS.

\section{Resultados y discusión}

Este estudio fue realizado para evaluar la especie Pseudomona spp., asociado a parámetros físico químico en la estación seca y lluviosa en aguas subterráneas de la región de Azuero.

Se realizó comparación de la ocurrencia de P. aeruginosa en época seca y época lluviosa de la región de Azuero. De igual manera se compara parámetros físico químicos tales como alcalinidad, Cloro Residual, Conductividad y pH y ver de manera gráfica que relación toma el crecimiento de la bacteria P. aeruginosa en base a los parámetros físico químicos y a la época en la cual fueron tomadas las muestras.

También se evaluó de manera exhaustiva que los parámetros más relevantes para nuestro estudio fueron el Cloro Residual y la conductividad, razón por la cual se comparó mediante gráficas, el crecimiento de P. aeruginosa frente a Cloro Residual y Conductividad tomando en cuenta las épocas para confirmar que tanto influían el crecimiento de la bacteria en estudio, para ambas provincias.

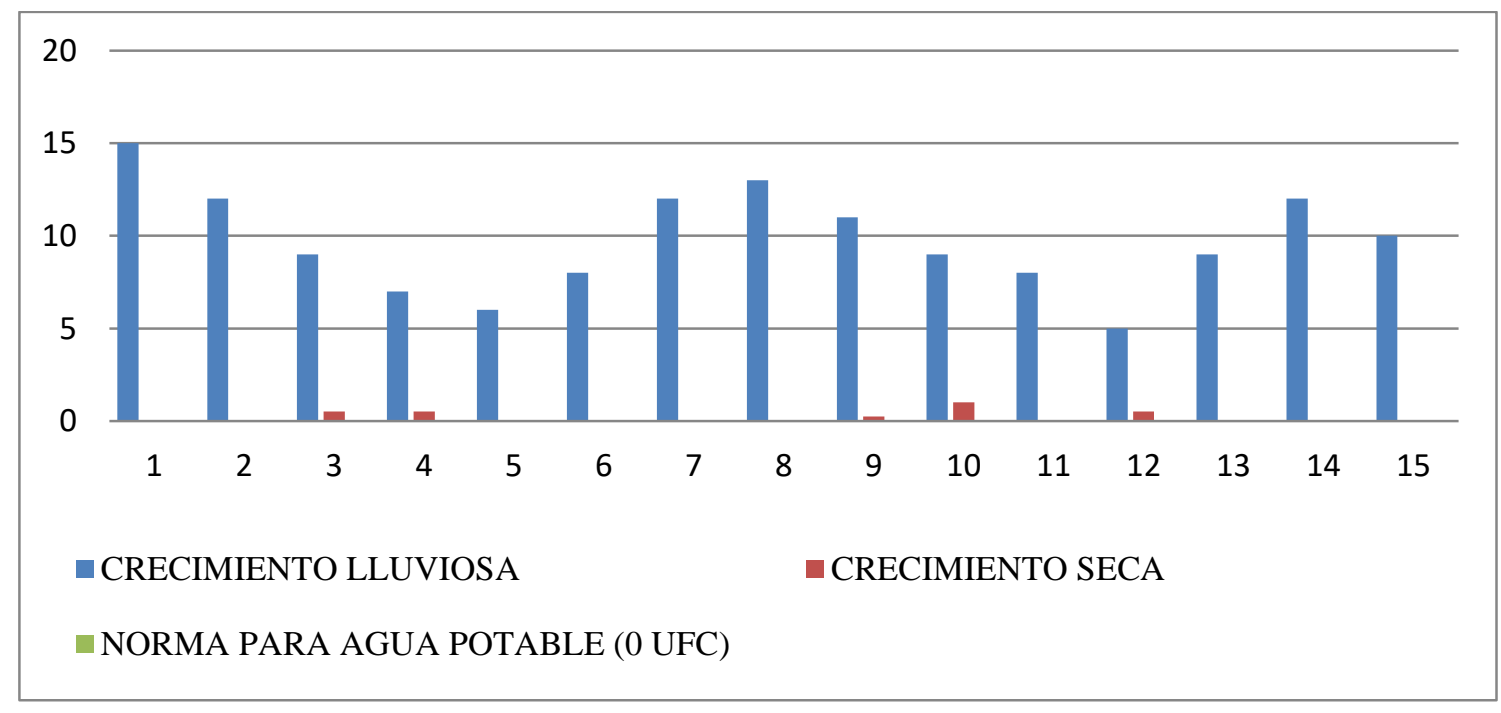

Figura $\mathbf{N}^{\mathbf{0}}$ 1. Crecimiento de Pseudomona aeruginosa en época seca y época lluviosa de la Provincia de Herrera. 


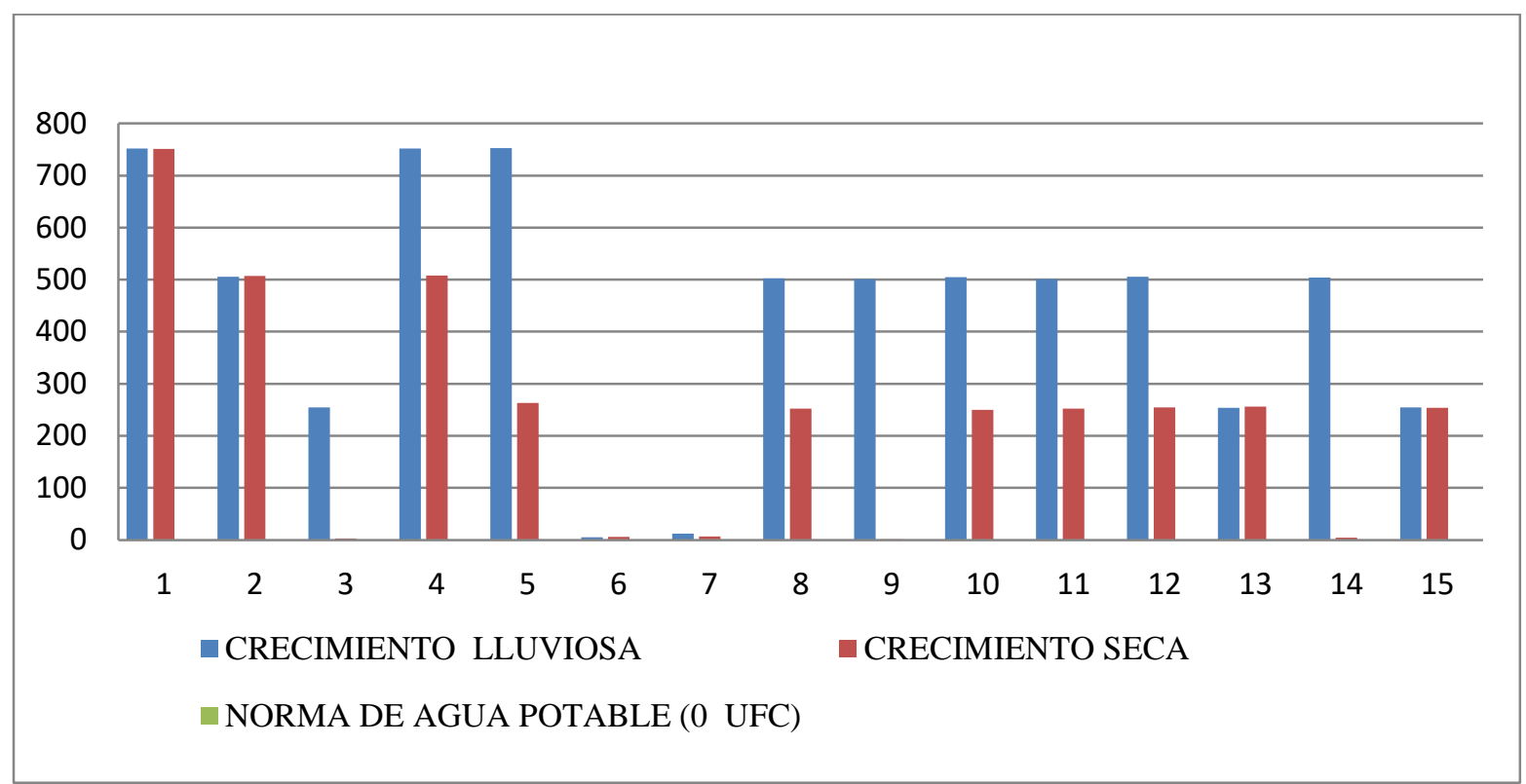

Figura $\mathbf{N}^{\mathbf{0}}$ 2. Crecimiento de Pseudomona aeruginosa en época seca y época lluviosa de la Provincia de Los Santos.

Con respecto a los resultados obtenidos se llega a observar que los valores de $P$. aeruginosa en cuanto a la época lluviosa fue alto su crecimiento para ambas provincias, mientras que en la estación seca el crecimiento fue menor en la provincia de Herrera, sin embargo, en la provincia de Los Santos permanece con valores significativos de igual manera altos a los de la época lluviosa.

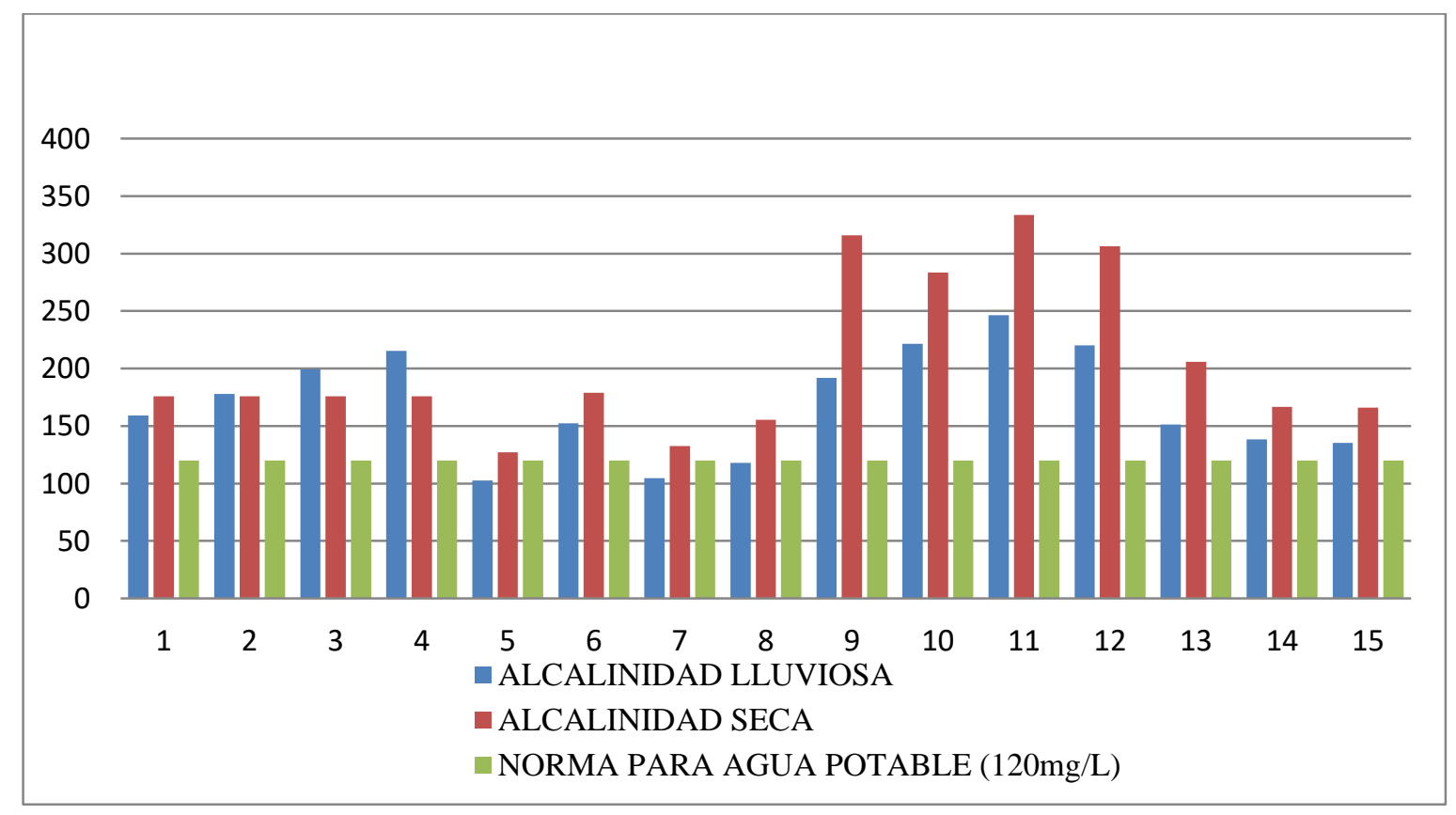

Figura $\mathbf{N}^{\mathbf{o}}$ 3. Comparación de niveles de Alcalinidad en época seca y época lluviosa de la Provincia de Herrera. 


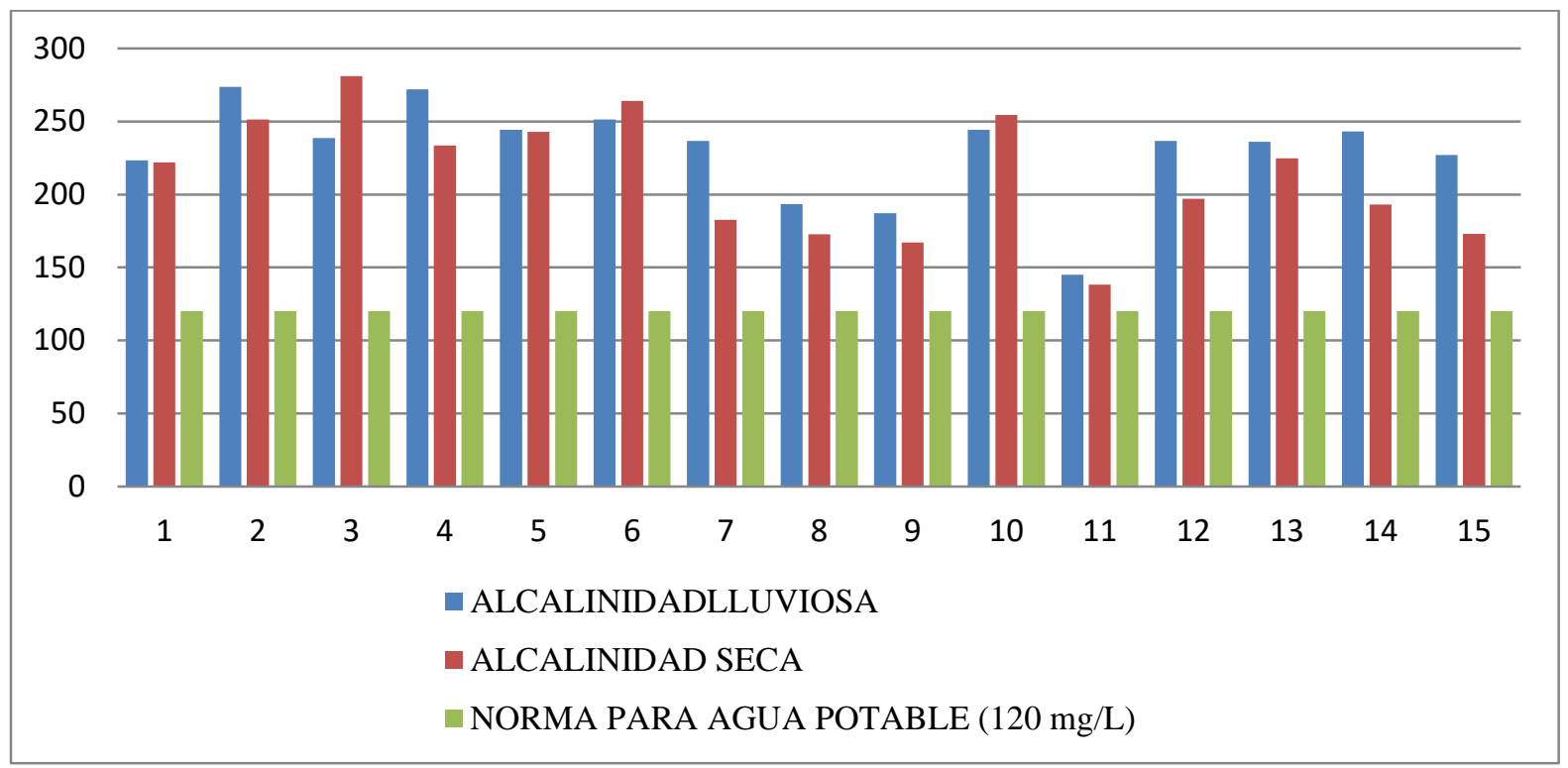

Figura $\mathbf{N}^{\mathbf{0}}$ 4. Comparación de niveles de Alcalinidad en época seca y época lluviosa de la Provincia de Los Santos.

En estas graficas muestran estadísticamente que los niveles de Alcalinidad para ambas provincias sobrepasan los valores máximos requeridos por la Norma de Calidad de Agua Potable DGNTCOPANIT 23-395-99 tanto en época lluviosa como seca.

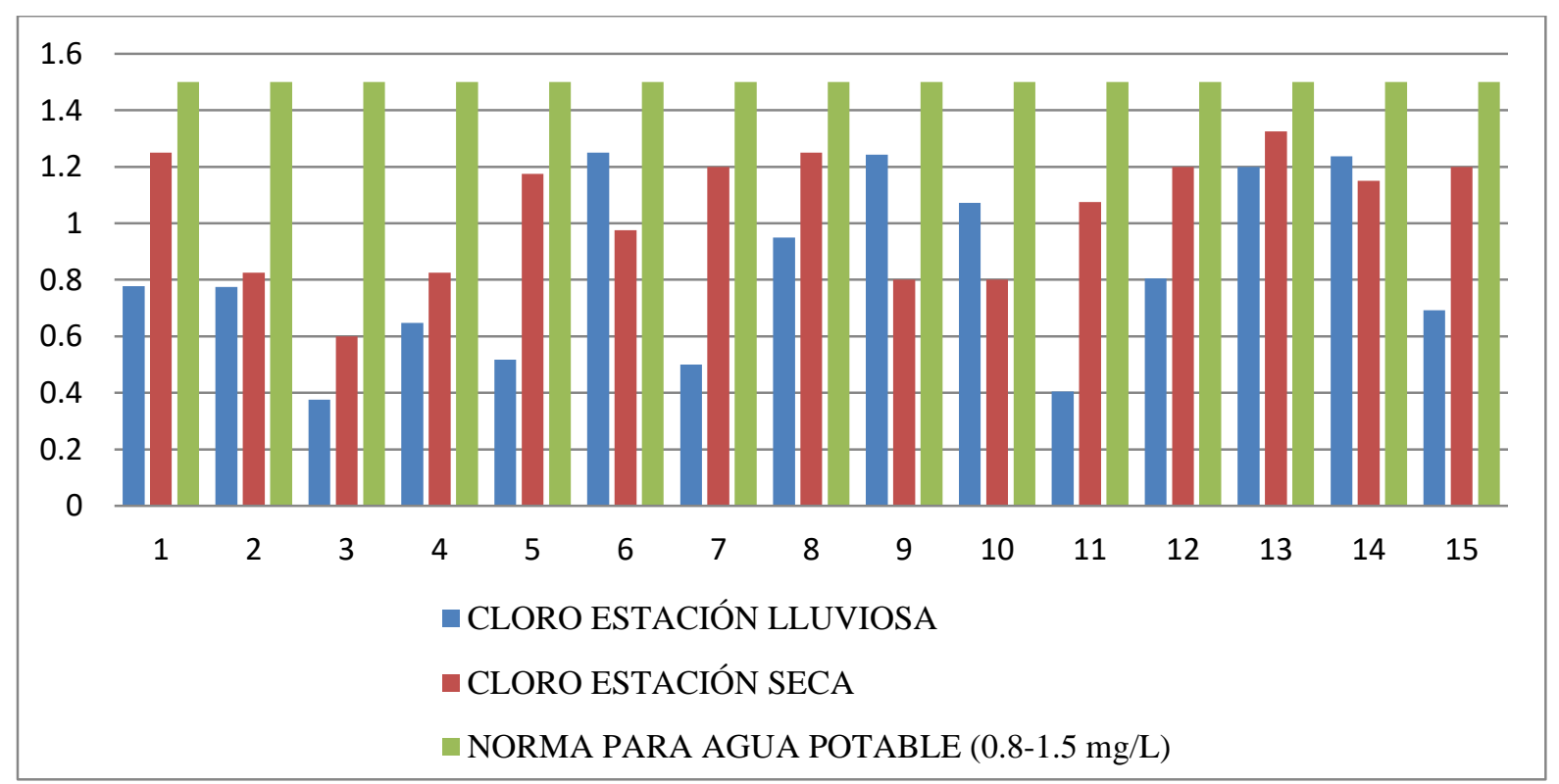

Figura $\mathbf{N}^{\mathbf{0}}$ 5. Comparación de niveles de Cloro Residual en época seca y época lluviosa de la Provincia de Herrera. 


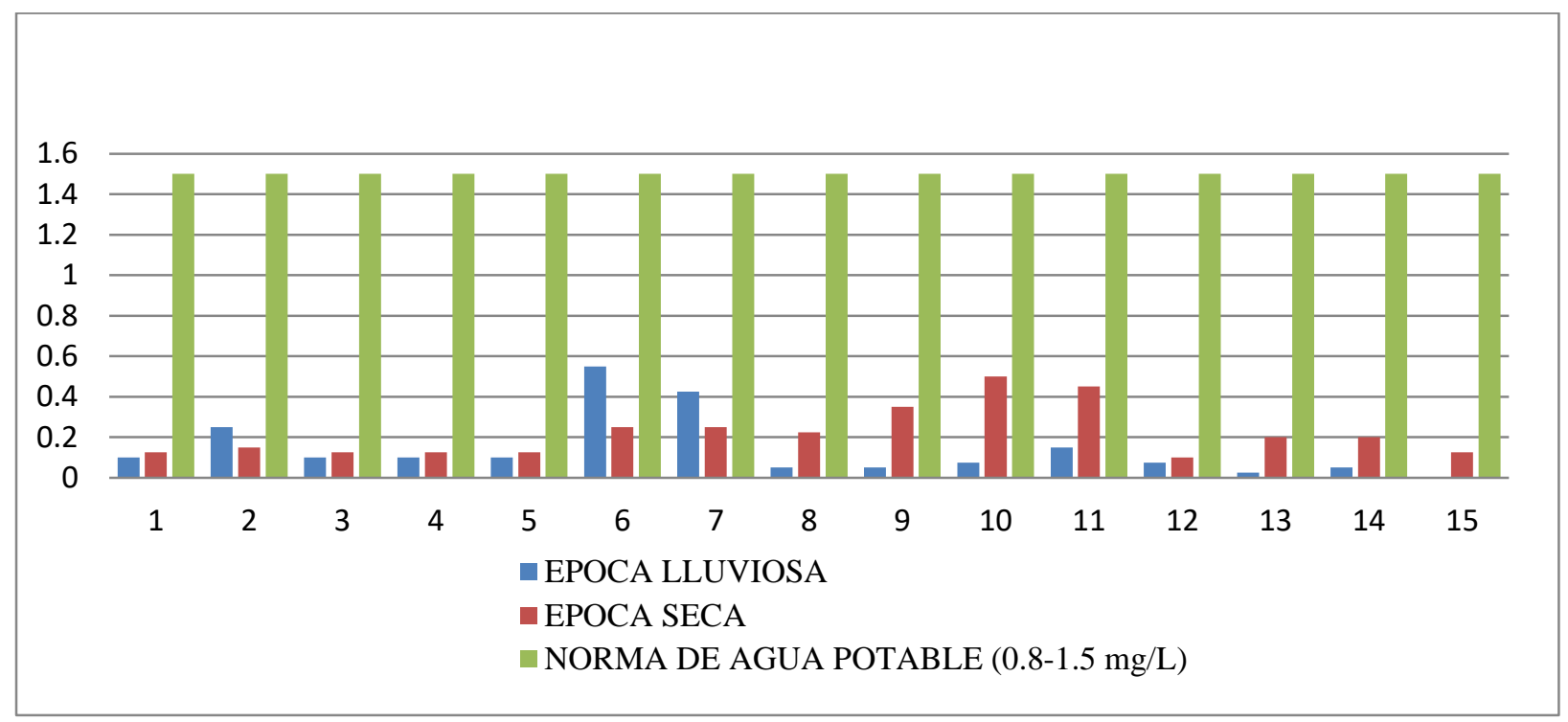

Figura $\mathbf{N}^{\mathbf{0}}$ 6. Comparación de niveles de Cloro Residual en época seca y época lluviosa de la Provincia de Los Santos.

Estas graficas muestran estadísticamente que los niveles de Cloro Residual para la provincia de Los Santos no cumplen con los valores máximos requeridos por la Norma de Calidad de Agua Potable DGNT-COPANIT 23-395-99, en lo que concierne a las épocas en estudio. Sin embargo, podemos señalar que la Provincia de Herrera con respecto a este parámetro físico si cumplen con los valores máximos requeridos por la Norma antes mencionada.

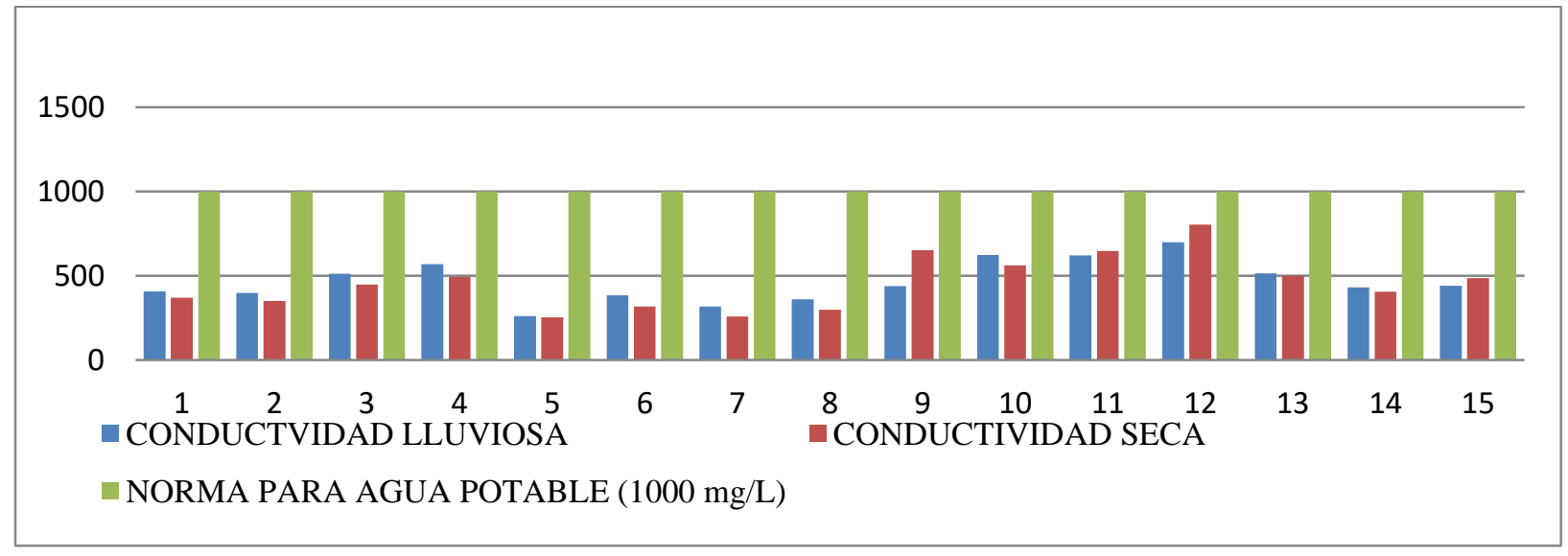

Figura $\mathbf{N}^{\mathbf{0}}$ 7. Comparación de niveles de Conductividad en época seca y época lluviosa de la Provincia de Herrera. 


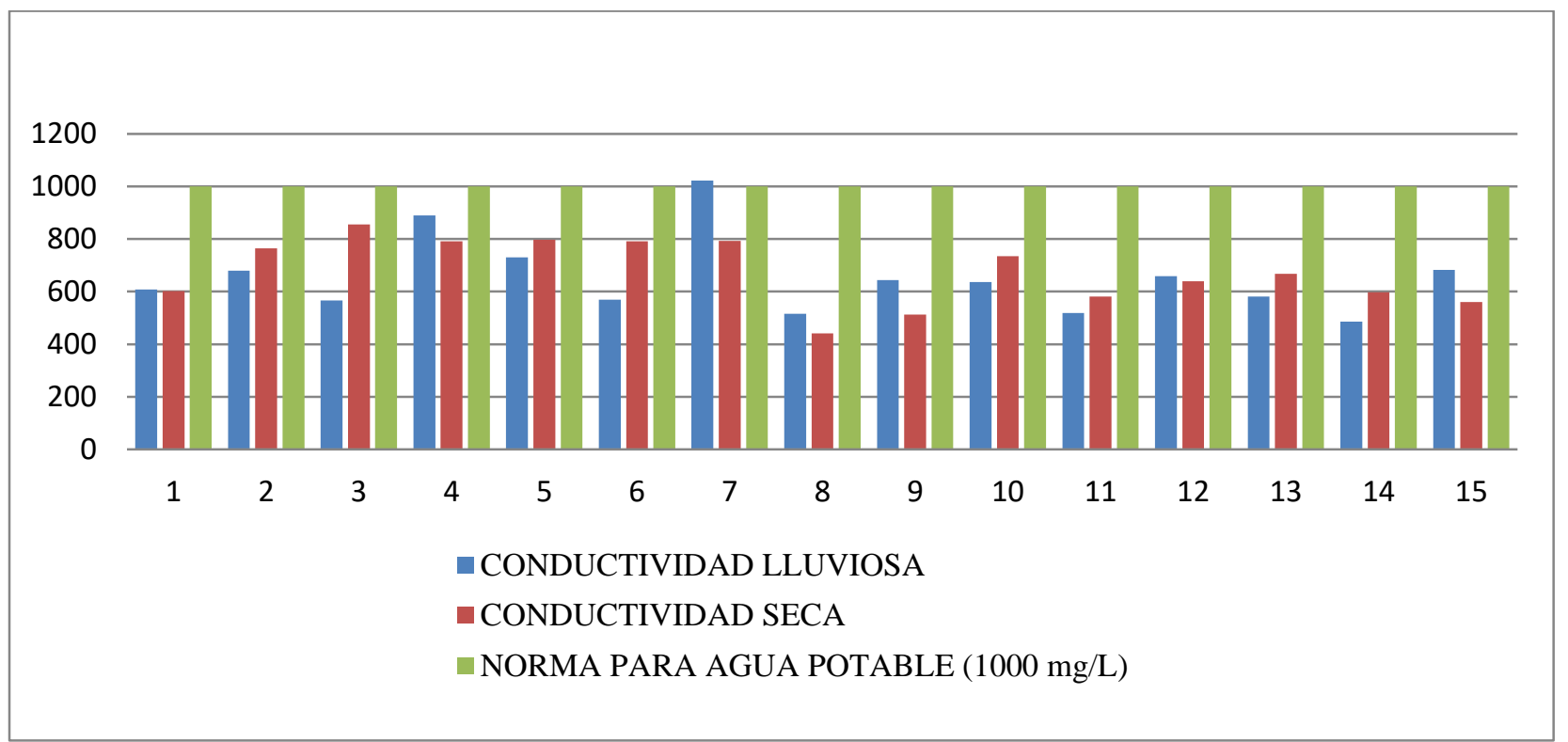

Figura $\mathbf{N}^{\mathbf{0}}$ 8. Comparación de niveles de Conductividad en época seca y época lluviosa de la Provincia de Los Santos.

Con respecto a los resultados obtenidos se llega a observar que los valores de conductividad para ambas provincias cumplen con los valores máximos requeridos por la Norma de Calidad de Agua Potable DGNT-COPANIT 23-395-99 tanto en época lluviosa como seca.

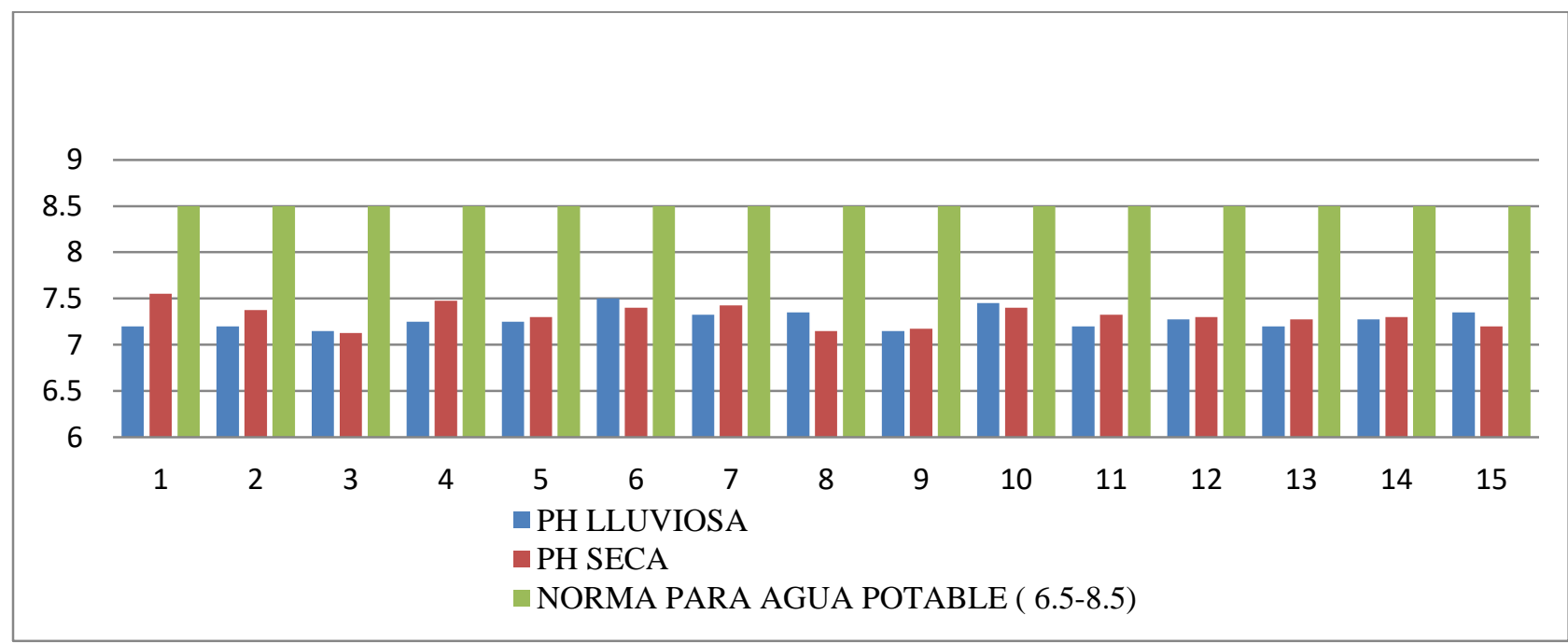

Figura $\mathbf{N}^{\mathbf{0}}$ 9. Comparación de niveles de pH en época seca y época lluviosa de la Provincia de Herrera. 


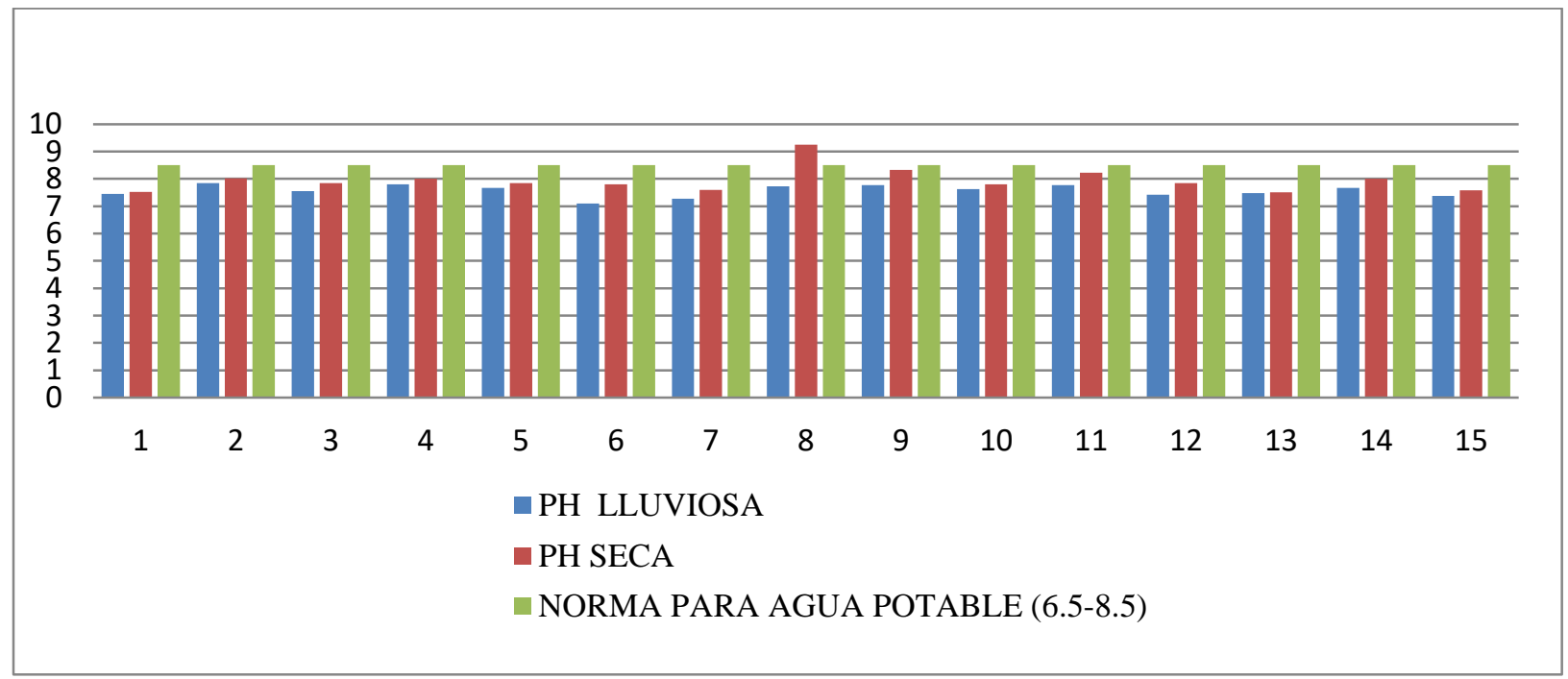

Figura $\mathbf{N}^{\mathbf{0}}$ 10. Comparación de niveles de $\mathrm{pH}$ en época seca y época lluviosa de la Provincia de Los Santos.

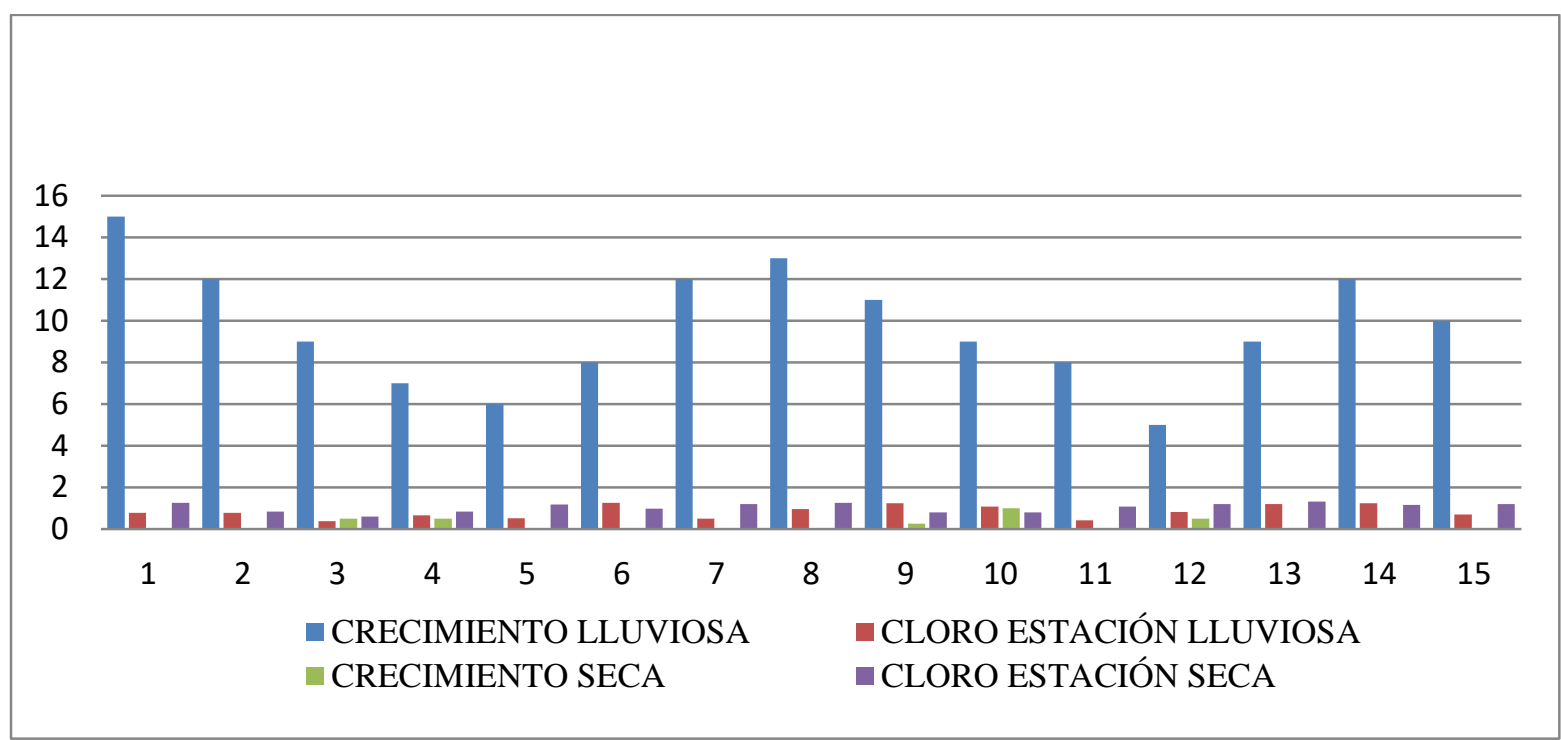

Figura $\mathbf{N}^{\mathbf{0}}$ 11. Comparación de Cloro Residual y Crecimiento de $P$. aeruginosa en época seca y época lluviosa de la Provincia de Herrera. 


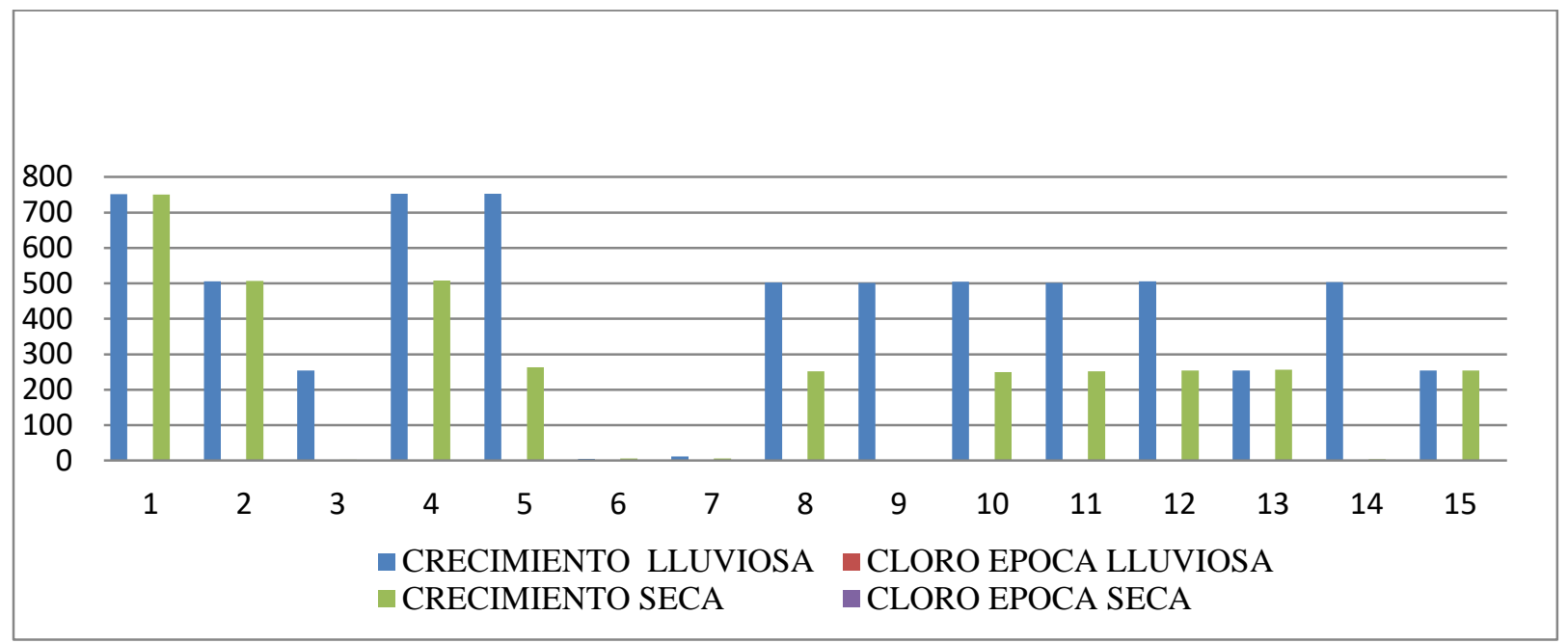

Figura $\mathbf{N}^{\mathbf{0}}$ 12. Comparación de Cloro Residual y Crecimiento de P. aeruginosa en época seca y época lluviosa de la Provincia de Los Santos.

Realizando comparación grafica de las provincias en estudio con lo que concierne a crecimiento vs cloro residual / época, ambas mantuvieron crecimiento en tanto en épocas lluviosa como en época seca. En lo que respecta al cloro residual ninguna de las Provincias cumplía con los valores máximos requeridos por la Norma de Calidad de Agua Potable (0.8-1.5 mg/L) DGNT-COPANIT 23-395-99

Siendo la provincia de Los Santos donde se incide un alto crecimiento de P. aeruginosa ya que los niveles de cloro residual para esta provincia son muy bajos a los niveles que la norma requiere. Sin embargo, en la Provincia de Herrera el crecimiento fue de mayor concentración en la época lluviosa mientras que en la época seca su crecimiento no fue elevado.

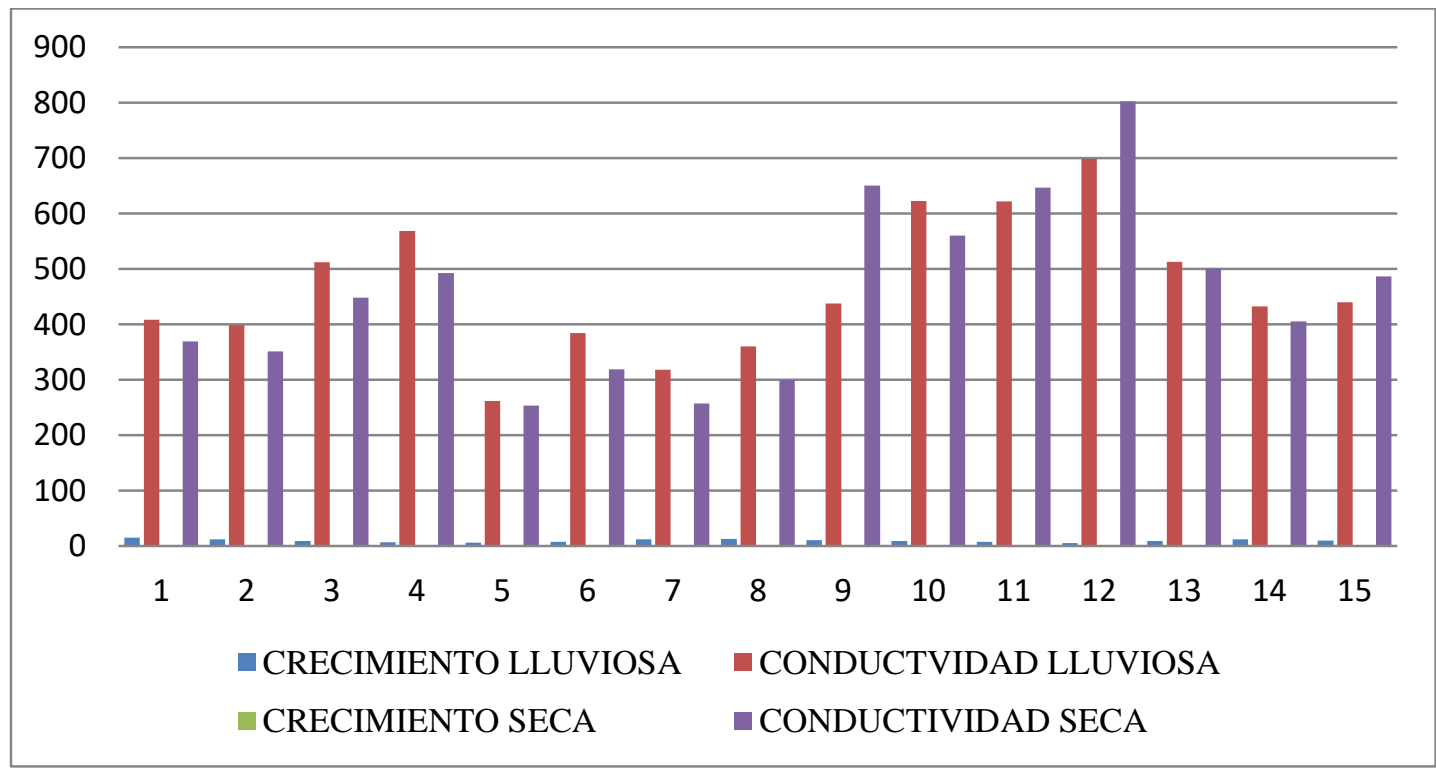

Figura $\mathrm{N}^{\mathrm{O}}$ 13. Comparación de Conductividad y Crecimiento de P. aeuroginosa en época seca y época lluviosa de la Provincia de Herrera. 


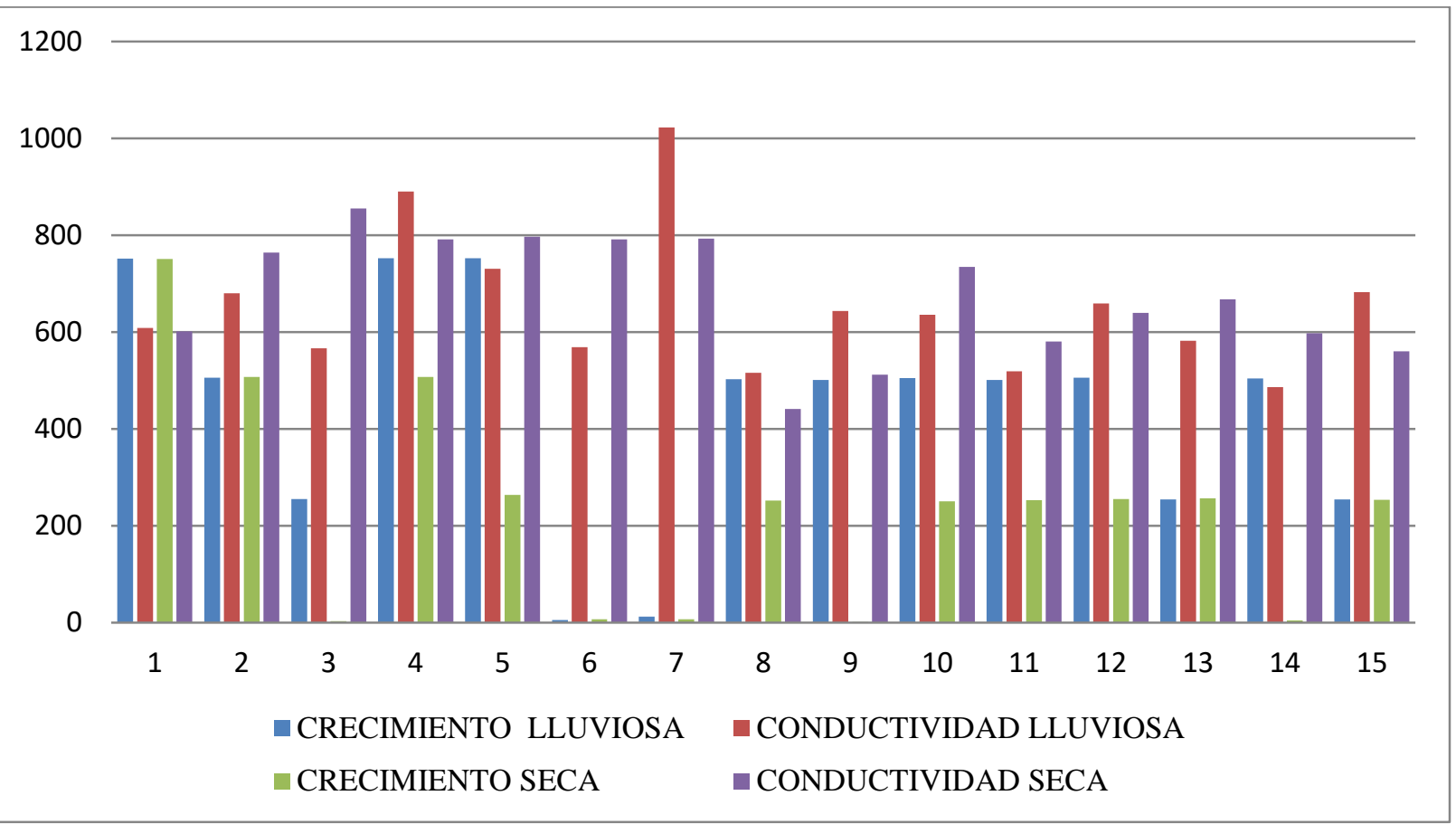

Figura $\mathbf{N}^{\mathbf{0}}$ 14. Comparación de Conductividad y Crecimiento de P. aeruginosa en época seca y época lluviosa de la Provincia de Los Santos.

En estas graficas se muestra estadísticamente que las provincias en estudio con lo que concierne a crecimiento vs conductividad / época, ambas mantuvieron crecimiento en épocas lluviosa como en época seca, pero permaneciendo con niveles más elevados de crecimiento la provincia de Los Santos.

\section{Conclusiones}

Los niveles de crecimiento de P. aeruginosa en los pozos subterráneos de la Provincia de Los Santos, indican que es mayor en cantidades significativas en ambas épocas en comparación con la provincia de Herrera.

Se manifestó que en la época lluviosa presentó una mayor ocurrencia de $P$. aeruginosa en comparación con la época seca, debido al incremento o actividad bacteriológica en los acuíferos filtrado por las aguas externas que van hacia el pozo.

Los parámetros fisicoquímicos se mantienen en este estudio constantes en las dos épocas de estudio, estas fueron: $\mathrm{pH}$ y conductividad en donde ambas se mantuvieron dentro de los valores máximos requeridos por la Norma de Calidad de Agua Potable DGNT-COPANIT 23-395-99.

Los parámetros fisicoquímicos con mayor importancia para nuestro estudio están el Cloro Residual y la conductividad. Siendo el cloro residual un parámetro clave para el control del crecimiento de $P$. aeruginosa. 
Concluimos que los niveles de cloro residual en ambas Provincias los valores máximos requeridos por la Norma de Calidad de Agua Potable DGNT-COPANIT 23-395-99, en lo que concierne a las épocas en estudio fueron, encontrados valores aceptables.

\section{Referencias}

Andía, Y. 2000. Tratamiento De Agua: Coagulación Floculación. Consultada el : 01 de Mayo de 2012.Disponible en :

http://www.frm.utn.edu.ar/archivos/civil/Sanitaria/Coagulaci $\% \mathrm{C} 3 \% \mathrm{~B} 3 \mathrm{n} \% 20 \mathrm{y} \% 20 \mathrm{Floculaci} \% \mathrm{C} 3 \%$ B3n $\% 20$ del $\% 20$ Agua $\% 20$ Potable.pdf.

Arcos, M., Ávila, S., Estupiñan, S., Gómez, A.2005. Indicadores microbiológicos de contaminación de las fuentes de agua. Consultada el: 13 de Junio de 2012.Disponible en:

http://www.unicolmayor.edu.co/invest_nova/NOVA/ARTREVIS2_4.pdf

Aurazo, M.2004.Manual para análisis básicos de calidad del agua de bebida. Consultada el: 17 de Junio de 2012. Disponible en: http:/ / es.scribd.com/doc/22227853/22/Metodo-de-filtro-demembrana-Metodo-tradicional http://es.scribd.com/doc/22227853/22/Metodo-de-filtro-demembrana-Metodo-tradicional

Aznar, A., Barba, A.2000. Determinación De Los Parámetros Físico-Químicos De Calidad De Las Aguas. Consultada el : 22 de Mayo de 2012.Disponible en: http://ocw.uc3m.es/ingenieriaquimica/ingenieria-ambiental/otros-recursos-1/OR-F-001.pdf

Bartha, R., Atlas, R .2011 1998.Ecologia microbiana y microbiología ambiental. $4^{a}$ ed. Microbial Ecology Fundamentals and applications. Consultada: el 18 de Junio de 2012.

Barrenchea, A. 2011.Aspectos Fisicoquímicos De La Calidad Del Agua. Consultada el: 22 de Mayo de 2012.Disponible en: http:/ / www.bvsde.ops-

oms.org/bvsatr/fulltext/tratamiento/manualI/tomoI/uno.pdf

Biosca, A. 1997. Mentor Enciclopedia Temática Estudiantil Océano, MCMXCVII Océano Grupo Editorial S. A Barcelona España.págs 346, 347, 547, 548,549. Consultada el: 31 de Marzo de 2012.

Burgos, G., Sevilla, L. 2008.Ecología y salud. 3raEdición.Editorial Mc Graw Hill interamericana editores S. A de C.V. págs. 162-166.Consultada el: 31 de Marzo de 2012.

Blessler, D., Balzer, M., Dannehl, A., Fleming. Wingender, J.2009. Persistence of Pseudomonas aeruginosa in drinking-water biofilms on elastomeric material. Consultada el: 29 de Abril de 2011. Disponible en: http://www.iwaponline.com/ws/00901/0081/009010081.pdf

Camacho, A., Giles, M., Ortegón, A., Serrano, B., Velásquez, O.2009. Método para la determinación de bacterias coliformes, coliformes fecales y Escherichia coli por la técnica de diluciones en tubo múltiple (Número más Probable o NMP).Consultada el:12 de Junio de 2012.Disponible en: 
http://depa.pquim.unam.mx/amyd/archivero/TecnicBasicas-Colif-tot-fecales-EcoliNMP_6529.pdf

Castillo, C.2003. Presencia de Biofilm en el sistema de transporte de agua interno de las unidades dentales. Tesis de graduación. Universidad Francisco Marroquín. Guatemala. Consultada el: 01 de Julio de 2012. Disponible en: http://www.tesis.ufm.edu.gt/pdf/3710.pdf

Caro, N. 2006. Validación de las pruebas de esterilidad por la técnica de filtración de membrana y endotoxinas bacterianas por el método de LAL en tres productos farmacéuticos. Tesis de graduación. Universidad Javeriana. Bogotá. Colombia. Consultada el: 18 de junio de 2012. Disponible en: http://www.javeriana.edu.co/biblos/tesis/ciencias/tesis272.pdf

Carvajal, A.2012. Agentes bacterianos asociados al agua de consumo humano. Consultada el: 9 de Julio de 2012. Disponible en: http://www.rscmv.org.ve/pdf/noticias_epidemologicas37.pdf

CATIE Panamá, 2009. Contribuyendo en el manejo integral de la cuenca del río La Villa. Consultada el :15 de Abril de 2012.Disponible en :

http://www.catie.ac.cr/BancoMedios/Documentos\%20PDF/infopan_mayo2009_contribu.pdf

Cornejo, M.2004.Manual de laboratorio. Microbiología Ambiental de Aguas Universidad de Panamá. Págs. 26, 27, 30,38. Consultada el: 01 de mayo de 2012.

Coutiño, M. 2008. Revista Médica de la Universidad Veracruzana. Agua como un Riesgo para la Salud. Vol. 8 núm. 1 consultada el 19 de septiembre de 2010. Disponible en: http://www.uv.mx/rm/num anteriores/revmedica vol8 num1/editorial/

De Sousa, C., Correia, A., Colmenares, C.2010. Corrosión e incrustaciones en los sistemas de distribución de agua potable revisión de las estrategias de control. Boletín de Malariología y Salud Ambiental.Vol. I, N² 2 . Consultada el: 01 de Julio de 2012. Disponible en: http://www.scielo.org.ve/pdf/bmsa/v50n2/art03.pdf.

De Sousa, C., Correia, A., Colmenares, C.2008. Contaminación bacteriológica en los sistemas de distribución de agua potable: Revisión de las estrategias de control. Boletín de Malariología y Salud Ambiental. Vol. XLVIII, N¹. Consultada el: 01 de Julio de 2012. Disponible en: http://www.scielo.org.ve/pdf/bmsa/v48n1/art02.pdf

Forbes, B., Sahm, D., Weissfeld, A.2009.Diagnostico Microbiologico.12a ed. Editorial Medica Panamericana. Buenos aires. Argentina. Consultada el: 7 de Julio de 2012. Disponible en: http:/ / books.google.com.pa/books?id=239cauKqSt0C\&pg=PA81\&lpg=PA81\&dq=Tincion + de $+g$ ram\&source $=$ bl\&ots $=2$ Ofwlc6DLi\&sig $=71 \mathrm{Wbse} 5$ x4jGcQJNBN6Rux8r_3OE\&hl=es419\&sa =X\&ei=JUP6T6a3OoO88AS8sozGBg\&ved=0CFkQ6AEwCA 
Galvín, R. 2006.Fisicoquímica y microbiología de los medios acuáticos: tratamiento y control de la calidad de las aguas. España. Ediciones Díaz de Santos. Consultada el: 26 de Junio de 2011.

Disponible en:

http:/ /books.google.com.pa/books?id=k8blixwJzYUC\&pg=PR13\&lpg=PR13\&dq=Fisicoquimica

$+\mathrm{y}+$ microbiologia $+\mathrm{de}+$ los + medios + acuaticos ++ tratamiento $+\mathrm{y}+$ control $+\mathrm{de}+\mathrm{la}+$ calidad $+\mathrm{de}+\mathrm{las}+\mathrm{a}$

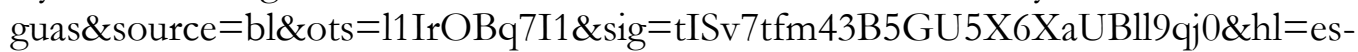

419\&sa $=$ X\&ei $=$ EbXzT7rzIZOs8ASel-

$\mathrm{XxBg \& ved=0CFEQ6AEwAQ \#} \mathrm{v}=$ onepage\&q $=$ Fisicoquimica $\% 20 \mathrm{y} \% 20$ microbiologia $\% 20 \mathrm{de} \% 201 \mathrm{o}$ $\mathrm{s} \% 20$ medios $\% 20$ acuaticos $\% 20 \% 20$ tratamiento $\% 20 \mathrm{y} \% 20$ control $\% 20 \mathrm{de} \% 20 \mathrm{la} \% 20$ calidad $\% 20 \mathrm{de} \% 20$ las $\% 20$ aguas\&f $=$ false

Gerba, Ch., Mena, K.2009.Risk assessment of Pseudomonas aerugionosa in water. Rev. Environ Contam Toxicol. Vol. 201, pp. 71-115. Consultada el: 4 de Mayo de 2011. Disponible en: http://www.ncbi.nlm.nih.gov/pubmed/19484589

Guevara.A.1996.Métodos de análisis para la evaluación de la calidad del agua. Consultada el: 7 de Julio de 2012. Disponible en: http://www.bvsde.paho.org/bvsacd/scan2/031279/031279.pdf

Gobernado, M. 2003.Identificacion bacteriana. Consultada el: 11 de Julio de 2012. Disponible en : http://www.elsevier.es/sites/default/files/elsevier/pdf/28/28v21 nSupl.2a13059086pdf001.pdf

HACH, 1993. Laboratorios Ambientales de microbiología. Manual de instrumentos y procedimientos. USA. Extraída el: 17 de junio de 2012. Págs. 19.

Herrera, J., Sánchez. 2005.Analisis de la calidad microbiológica del agua potable provenientes de las redes de distribución del área metropolitana y la chorrera. Trabajo de graduación. Universidad de Panamá. Panamá. Págs. 15-17 Consultada el: 19 de mayo de 2012. 